\title{
Characteristics of a New Plastic Explosive Named EPX-1
}

\begin{abstract}
Ahmed Elbeih
Military Technical College, Kobry Elkobbah, Cairo, Egypt

Correspondence should be addressed to Ahmed Elbeih; elbeih.czech@gmail.com

Received 3 December 2014; Accepted 23 March 2015

Academic Editor: Ewa Schab-Balcerzak

Copyright (C) 2015 Ahmed Elbeih. This is an open access article distributed under the Creative Commons Attribution License, which permits unrestricted use, distribution, and reproduction in any medium, provided the original work is properly cited.

EPX-1 is a new plastic explosive (in the research stage) which has been prepared for military and civilian applications. EPX-1 explosive contains pentaerythritol tetranitrate (PETN) with different particle size as explosive filler bonded by nonenergetic thermoplastic binder plasticized by dibutyl phthalate (DBP). In this paper, the production method of EPX-1 was described. The crystal morphology was studied by scanning electron microscope (SEM). Heat of combustion was determined experimentally. The compatibility of PETN with the polymeric matrix was studied by vacuum stability test. Sensitivities to impact and friction were measured. The detonation velocity was measured experimentally and the detonation characteristics were calculated by EXPLO5 thermodynamic code. For comparison, Semtex 1A, Semtex 10, Formex P1, and Sprängdeg m/46 were studied. It was concluded that PEX-1 has compatible ingredients, it has the highest detonation velocity of all the studied plastic explosives, and its sensitivity is in the same level of the studied plastic explosives except Semtex 1A.
\end{abstract}

\section{Introduction}

Development of plastic explosives is a topic of interest for our team. Several countries all over the world produce plastic explosives containing different explosive fillers bonded by different polymeric matrices. Many researches have been reported about the development of plastic explosives including the preparation, sensitivity, and detonation characteristics of plastic explosives based on several interesting nitramines [1-7]. The effect of plasticizers on the thermal behaviour of the plastic explosives has been studied [8]. The thermal stability and decomposition kinetics of selected nitramines bonded by different polymeric matrices have been studied using different techniques [9-15] and the low temperature thermolytic behaviour has been evaluated by vacuum stability test $[16,17]$.

Semtex 10 and Semtex 1A are plastic explosives produced by Explosia Company, Czech Republic. They contain pentaerythritol tetranitrate (PETN) as explosive filler bonded by nonexplosive plasticizer; they are used in demolition work and underwater blasting operations [18]. Formex P1 is a French plastic explosive which contains PETN bonded by styrene butadiene rubber and plasticized by oily material $[9$, 16]. Sprängdeg $\mathrm{m} / 46$ is a Swedish plastic explosive containing PETN bonded by highly viscous oily material $[1,7]$.
The aim of this work is to discuss the preparation and characterization of our new plastic explosive named EPX-1. For comparison, the characteristics of Semtex 1A, Semtex 10, Formex P1, and Sprängdeg $\mathrm{m} / 46$ were reported and discussed. The crystal morphology, sensitivity, and detonation velocity of the prepared EPX-1 were studied and discussed. Heat of combustion and elemental analysis of the sample were determined in order to calculate the heat of formation of EPX-1. The detonation parameters were calculated by EXPLO5 thermodynamic code [19].

\section{Preparation of EPX-1}

EPX-1 was prepared in Heliopolis Company for Chemical Industries, Egypt. PETN is a product of the company which has two grades of mean particle size of 16 and $300 \mu \mathrm{m}$, respectively. Dibutyl phthalate is a product of Jai Enterprises, Delhi, India. Nonenergetic thermoplastic binder (unpublished details) was prepared. The preparation process is based on direct mixing of PETN with a polymeric matrix (binder swelled by dibutyl phthalate). PETN $86 \mathrm{wt} \%$ was mixed with the polymeric matrix $14 \mathrm{wt} \%$ at $60^{\circ} \mathrm{C}$ for $45 \mathrm{~min}$ under vacuum using stainless steel vertical mixer. The addition of 


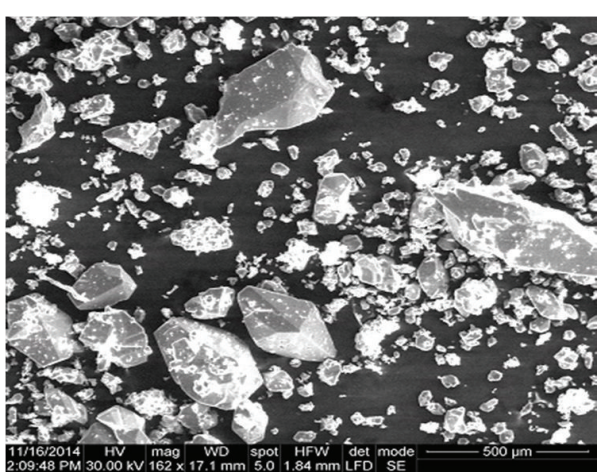

(a)

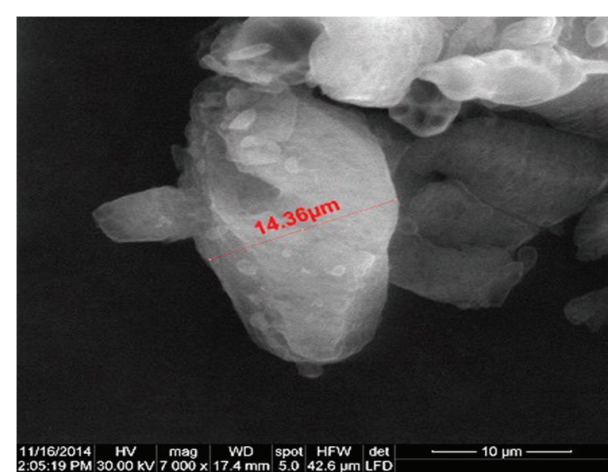

(b)

FIGURE 1: SEM photos of PETN crystals.

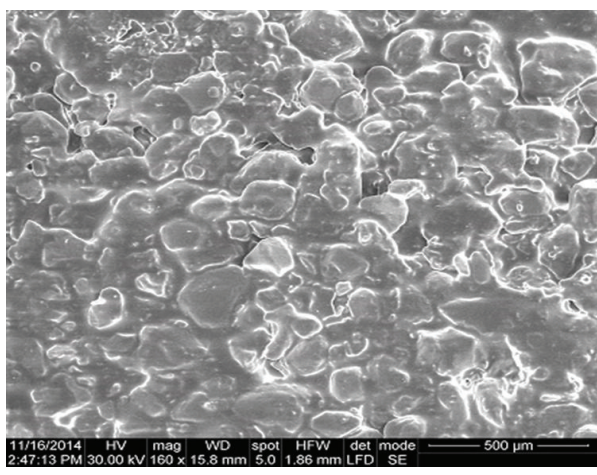

(a)

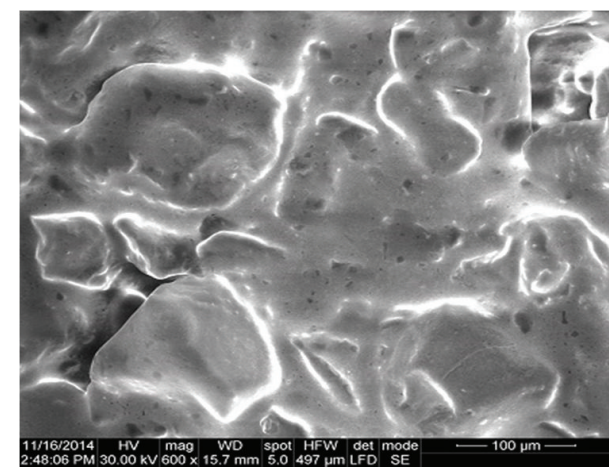

(b)

Figure 2: SEM photos of the prepared EPX-1 explosive.

PETN to the polymeric matrix was in three portions each after $15 \mathrm{~min}$. The obtained product was prepared in the form of blocks, each having mass of $200 \mathrm{~g}$. In order to measure the detonation velocity, cylinders of plastic explosives were prepared in the form of cylinders.

\section{Crystal Morphology Study}

Scanning electron microscope (SEM) model Inspect S produced by FEI Company was used to study the morphology of the crystals and their quality of coating. Sample of PETN crystals and a thin layer of the prepared plastic explosive were tested. SEM photographs of PETN are presented in Figure 1.

Figure 1(a) showed that PETN had different crystal sizes where the crystals are not regular and have edges and corners. In order to check the surface of the crystal clearly, Figure 1(b) presented the image with high magnification concentrated on one crystal of particle size around $14 \mu \mathrm{m}$. The surface is not smooth and there are cracks on the crystal surface. The recrystallization process of PETN was technical method and was used in large quantity (minimum $200 \mathrm{~kg}$ ). As a result, controlling of the crystal shapes is difficult. In order to check the coating of the crystals, SEM photographs of EPX-1 are presented in Figure 2. Figure 2(a) gave indication that PETN crystals were coated completely by the polymeric matrix. There are no crystals appearing outside the polymeric matrix. In order to confirm this result, Figure 2(b) showed a magnified resolution of EPX-1 where the surfaces of the crystals are completely coated. These results confirmed that the new polymeric matrix was able to bond the crystals and sufficiently coat their surfaces.

\section{Elemental Analysis}

The Perkin Elmer $2400 \mathrm{CHNS} / \mathrm{O}$ elemental analyzer was used to detect the \% of $\mathrm{C}, \mathrm{H}$, and $\mathrm{N}$ in the prepared samples which were needed for the theoretical calculation of the detonation parameters of the prepared sample. The results of the elemental analysis were recalculated to match the $\mathrm{N}$ content to the individual explosive and reported in Table 1. The summary formula calculated in this way was used as if it was individual explosive and it was used in order to calculate the detonation parameters of EPX-1.

\section{Heat of Combustion}

Automatic Combustion Calorimeter MS10A was used for measuring the heat of combustion of the samples. The sample was prepared and placed in a bomb filled with excess of oxygen [20] where the data obtained from the measurements 
TABLE 1: The data required for calculation of detonation characteristics.

\begin{tabular}{lccccc}
\hline Number & Explosive type & Formula & $\begin{array}{c}\text { Mol. weight } \\
\left(\mathrm{g} \cdot \mathrm{mol}^{-1}\right)\end{array}$ & $\begin{array}{c}\text { Heat of } \\
\text { combustion }\left(\mathrm{J} \cdot \mathrm{g}^{-1}\right)\end{array}$ & $\begin{array}{c}\text { Heat of formation } \\
\left(\mathrm{kJ} \cdot \mathrm{mol}^{-1}\right)\end{array}$ \\
\hline 1 & PETN [7] & $\mathrm{C}_{5} \mathrm{H}_{8} \mathrm{~N}_{4} \mathrm{O}_{12}$ & 316.15 & 8182 & -538.7 \\
2 & EPX-1 & $\mathrm{C}_{7.88} \mathrm{H}_{12.36} \mathrm{~N}_{4} \mathrm{O}_{12.59}$ & 364.58 & 11528 & -666.5 \\
3 & Semtex 1A [7] & $\mathrm{C}_{9.15} \mathrm{H}_{14.85} \mathrm{~N}_{4} \mathrm{O}_{11.42}$ & 362.22 & 14003 & -660.2 \\
4 & Semtex 10 [7] & $\mathrm{C}_{8.05} \mathrm{H}_{12.64} \mathrm{~N}_{4} \mathrm{O}_{12.37}$ & 363.38 & 11942 & -646.8 \\
5 & Formex P1 [25] & $\mathrm{C}_{8.26} \mathrm{H}_{13.98} \mathrm{~N}_{4} \mathrm{O}_{11.85}$ & 358.93 & 12943 & -613.2 \\
6 & Sprängdeg m/46 [7] & $\mathrm{C}_{8.10} \mathrm{H}_{12.81} \mathrm{~N}_{4} \mathrm{O}_{10.90}$ & 340.63 & 13179 & -539.2 \\
\hline
\end{tabular}

TABLE 2: The measured characteristics of the studied explosives.

\begin{tabular}{lccccc}
\hline Number & Explosive type & $\begin{array}{c}\text { Impact sensitivity } \\
(\mathrm{J})\end{array}$ & $\begin{array}{c}\text { Friction sensitivity } \\
(\mathrm{N})\end{array}$ & $\begin{array}{c}\text { Density } \\
\left(\mathrm{g} \cdot \mathrm{cm}^{-3}\right)\end{array}$ & $\begin{array}{c}\text { Detonation velocity measured } \\
\left(\mathrm{m} \cdot \mathrm{s}^{-1}\right)\end{array}$ \\
\hline 1 & PETN [1] & 2.9 & 44 & 1.70 & 8400 \\
2 & EPX-1 & 13.9 & 176 & 1.55 & 7636 \\
3 & Semtex 1A [1] & 21.1 & 187 & 1.47 & 7264 \\
4 & Semtex 10 [3] & 15.7 & 204 & 1.52 & 7486 \\
5 & Formex P1 [25] & 13.5 & 194 & 1.53 & 7544 \\
6 & Sprängdeg m/46 [1] & 14.2 & 183 & 1.52 & 7520 \\
\hline
\end{tabular}

was reported in Table 1. This data was used for calculation of the heat of formation of the samples which was used for the calculation of the detonation parameters.

\section{Compatibility of the Materials}

A vacuum stability test named STABIL, modernized apparatus STABIL 16-Ex [20] (manufactured by OZM Research; the original apparatus is described in [21]), was used to study the compatibility of the materials with each other. A mass of $2 \mathrm{~g}$ was prepared from the polymeric matrix and PETN. Also $4 \mathrm{~g}$ of the prepared plastic explosive EPX-1 was prepared. Tests were performed at $100^{\circ} \mathrm{C}$ for 48 hours. The samples in evacuated glass test tubes were placed into the heating block and heated to the desired temperature. Pressure transducers continuously estimated the pressure increase in the glass tubes. The results were in the form of time dependence of the gas pressure evolved per one gram of sample and the volume of gas produced per gram of sample was recorded. The result obtained for PETN was $0.54 \mathrm{~mL} \mathrm{~g}^{-1}$ (slightly higher than [22] which has $0.2-0.5 \mathrm{~mL} \mathrm{~g}^{-1}$ ), while the result for the polymeric matrix was $1.32 \mathrm{~mL} \mathrm{~g}^{-1}$. EPX-1 gave volume of gas equal to $0.79 \mathrm{~mL} \mathrm{~g}^{-1}$. The sum of the gas evolved by PETN and the polymeric matrix separately was $0.71 \mathrm{~mL} \mathrm{~g}^{-1}$ which means that EPX-1 has $0.07 \mathrm{~mL} \mathrm{~g}^{-1}$ in excess of the sum of the gas evolved by the separate components (higher than $5 \mathrm{~mL} \mathrm{~g}^{-1}$ is considered being incompatible). The results prove that PETN are compatible with the polymeric matrix of EPX-1.

\section{Sensitivity Measurement}

7.1. Impact Sensitivity Measurements. A standard impact tester with exchangeable anvil (Julius Peters [23]) was used with a $2 \mathrm{~kg}$ drop hammer; the amount of substance tested was $50 \mathrm{~mm}^{3}$. Probit analysis [24] was used to determine the probability levels for initiation. The sensitivity obtained was expressed as the drop energy versus percentage of initiation. Only the $50 \%$ probability of initiation has been used in this paper and is reported in Table 2.

7.2. Friction Sensitivity Measurements. A BAM friction test apparatus was used to determine the sensitivity to friction using the standard test conditions [23]. The sensitivity to friction was determined by spreading about $0.01 \mathrm{~g}$ of the studied explosive on the surface of the porcelain plate in the form of a thin layer. Different loads were used to change the normal force between the porcelain pistil and the plate. Sample initiation was observed through sound and smoke appearance or by the characteristic smell of the decomposition products. Using the Probit analysis [24], only the normal force at which $50 \%$ of initiations occurred is reported in Table 2 as the friction sensitivity.

A comparison between the results of impact and friction sensitivities is presented in Figure 3. All the studied plastic explosives are based on PETN and the comparison proved that all the polymeric matrices had a great effect on decreasing the impact and friction sensitivities of PETN. Regarding the friction sensitivity, all the studied samples have friction force which lies between 175 and $205 \mathrm{~N}$ as shown in the figure while PETN needs $44 \mathrm{~N}$ to initiate it. The results prove that the used polymeric matrices have nearly the same effect on decreasing the friction sensitivity of PETN. Regarding the impact sensitivity, all the studied plastic explosives except Semtex 1A have impact energy of initiation which lies between 13.5 and $15.7 \mathrm{~J}$ while Semtex $1 \mathrm{~A}$ needs higher impact energy $(21.1 \mathrm{~J})$ to initiate it. This result might be due to the high wt\% of the polymeric matrix in Semtex $1 \mathrm{~A}$ 
TABLE 3: The calculated detonation characteristics of the studied explosives.

\begin{tabular}{|c|c|c|c|c|c|c|}
\hline No. & Explosive type & Density $\left(\mathrm{g} \cdot \mathrm{cm}^{-3}\right)$ & $\begin{array}{l}\text { Detonation velocity } \\
\qquad\left(\mathrm{m} \cdot \mathrm{s}^{-1}\right)\end{array}$ & $\begin{array}{c}\text { EXPLO5 } \\
{\left[\left(D_{\text {calc }}-D_{\text {exp }}\right) / D_{\exp }\right] \times 100} \\
(\%)\end{array}$ & $\begin{array}{c}\text { Detonation } \\
\text { pressure }(\mathrm{GPa})\end{array}$ & $\begin{array}{l}\text { Detonation } \\
\text { heat }\left(\mathrm{J} \cdot \mathrm{g}^{-1}\right)\end{array}$ \\
\hline 1 & PETN [1] & 1.70 & 8350 & -0.6 & 28.62 & 6258 \\
\hline 2 & EPX-1 & 1.55 & 7398 & -3.1 & 21.17 & 5742 \\
\hline 3 & Semtex 1A [1] & 1.47 & 7014 & -3.4 & 17.52 & 5099 \\
\hline 4 & Semtex $10[3]$ & 1.52 & 7370 & -1.5 & 20.89 & 5708 \\
\hline 5 & Formex P1 & 1.53 & 7346 & -2.6 & 20.03 & 5411 \\
\hline 6 & Sprängdeg m/46 [1] & 1.52 & 7232 & -3.8 & 19.28 & 5345 \\
\hline
\end{tabular}

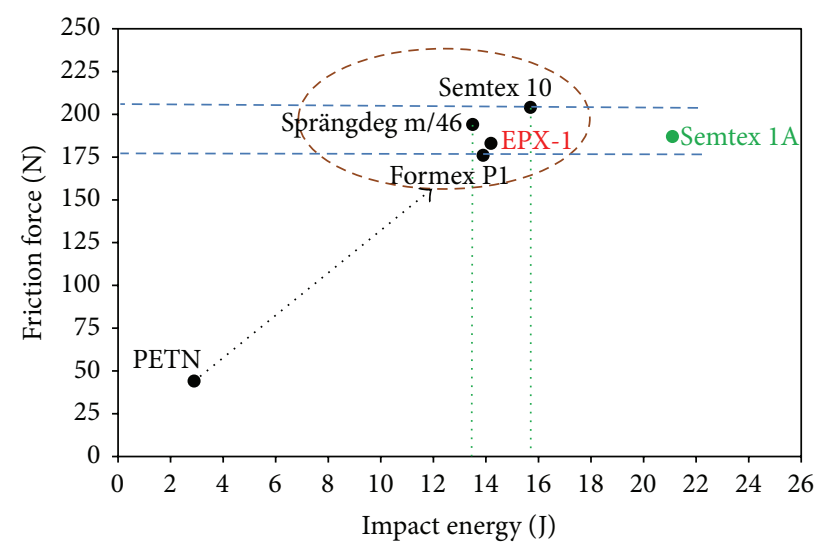

FIGURE 3: Comparison between the impact and friction sensitivities of all the studied samples.

(17 wt\%). EPX-1 lies on the same sensitivity level of the entire studied explosives except Semtex 1A which has lower impact sensitivity than the rest of the studied plastic explosives.

\section{Detonation Velocity Measurements}

The detonation velocity of the composition prepared was measured by an EXPLOMET-FO-2000 produced by KONTINITRO AG. The composition tested was prepared in the form of cylinder with $21 \mathrm{~mm}$ diameter and $300 \mathrm{~mm}$ length. Three optical sensors were placed in each charge, with the first sensor being placed at a distance of $100 \mathrm{~mm}$ from the surface containing the detonator. Each of the other two sensors was placed at a distance of $80 \mathrm{~mm}$ from the previous one. Charges were set off using detonator number 8 . Three measurements were performed for the composition and the mean value (maximum $\pm 68 \mathrm{~m} \mathrm{~s}^{-1}$ ) is reported in Table 2 .

The results prove that EPX-1 has the highest detonation velocity of all the studied plastic explosives. Figure 4 presents a relationship between the density and detonation velocity of the studied samples in order to compare the results.

It is clear from Figure 4 that there is a linear relationship between the loading density and the detonation velocity of all the studied samples. EPX-1 has the highest loading density and detonation velocity of all the studied plastic explosives. Formex P1 (PETN $87 \mathrm{wt} \%$ ) has higher content

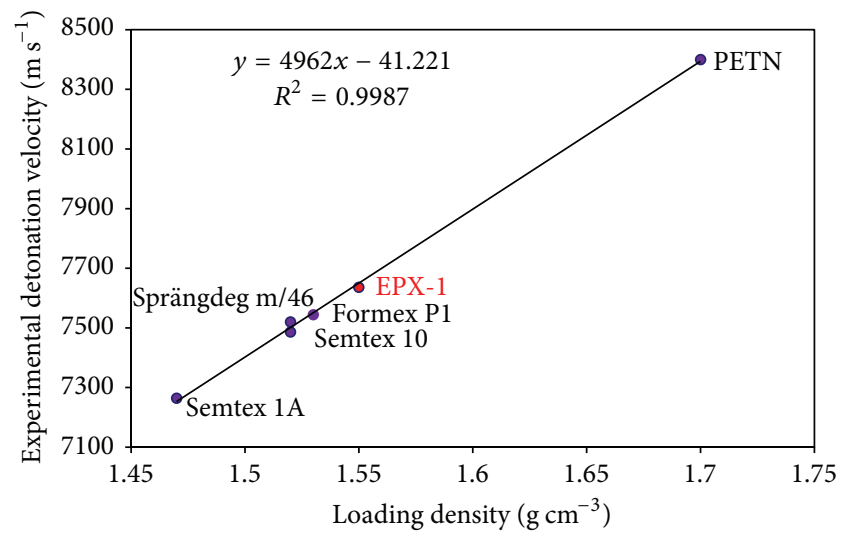

FIGURE 4: Relationship between the loading density and experimental detonation velocity of the studied samples.

of pure explosive than EPX-1 (PETN 86\%) but it has lower density and detonation velocity. This result proved that the used polymeric matrix of EPX-1 has less negative effect on the detonation velocity than Formex P1. As predicted, Semtex 1A has the least detonation velocity of all the studied samples.

\section{Calculation of the Detonation Characteristics}

The theoretical detonation characteristics (detonation velocity, $D$, heat of detonation, $Q$, and detonation pressure, $P$ ) of all the studied plastic explosives as well as PETN explosive were calculated by the use of EXPLO5 thermodynamic code [7]. BKWN set of parameters for the BKW EOS was applied; these parameters are $\alpha=0.5, \beta=0.298, \kappa=10.50$, and $\Theta=6620$. The calculated detonation characteristics of all the tested explosives are reported in Table 3. In order to check the accuracy of the calculations, a relationship between the calculated detonation pressure and the experimental density multiplied by the square of the detonation velocity is presented in Figure 5.

From Figure 5, a linear relationship proves the compatibility of the calculated results with the measured data. EPX-1 appeared to have the highest detonation pressure of all the studied plastic explosives and in the same level of Semtex 10 (85 wt\% PETN). Semtex 1A has the lowest detonation pressure of all the studied samples. Another relationship 


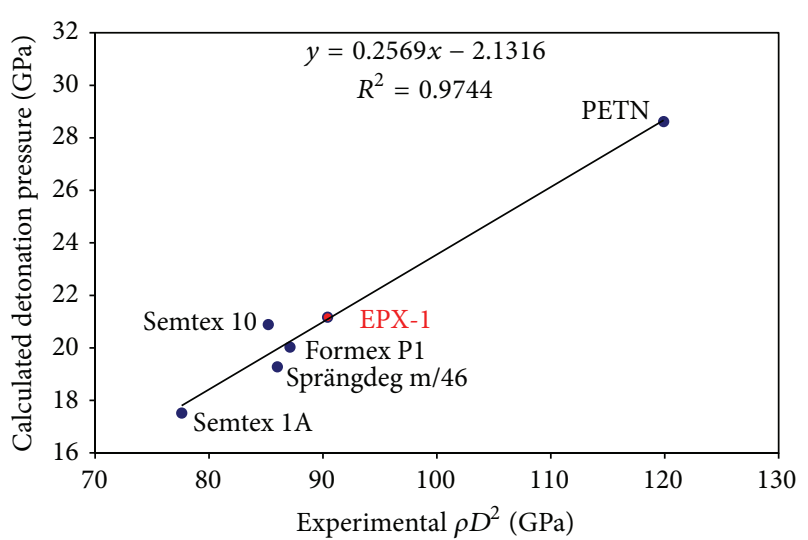

FIGURE 5: Relationship between the calculated detonation pressure and the experimental $\rho D^{2}$ ( $\rho$ : loading density; $D$ : experimental detonation velocity).

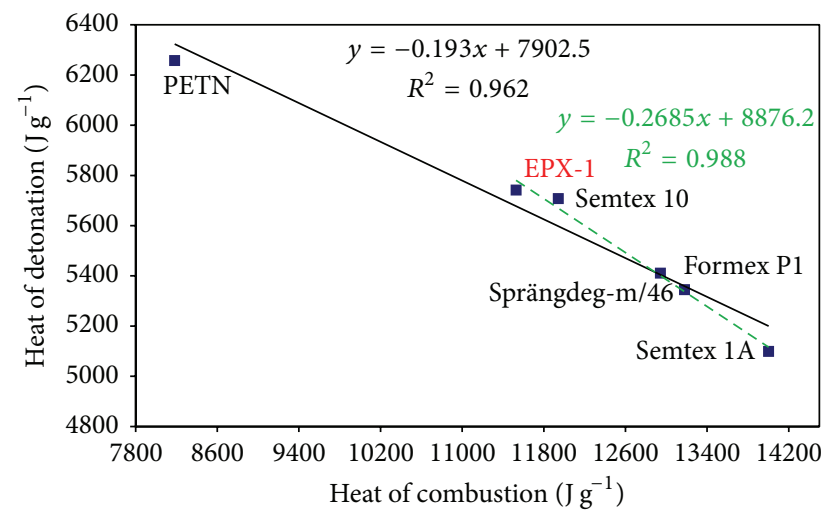

FIGURE 6: Relationship between the calculated heat of detonation and the measured heat of combustion of the studied samples.

between the calculated heat of detonation and the measured heat of combustion is presented in Figure 6. This figure proves the linear relationship between the heat of detonation and the heat of combustion of the studied samples. The dashed line represents the fitting of the studied plastic explosives without including PETN (pure explosive) while the solid line represents the fitting of all the studied samples. It is obvious that the correlation between the plastic explosives is of higher accuracy than that including the pure explosive. These results confirm the great influence of the polymeric matrix on the heat of detonation and combustion of the pure explosive. As the heat of combustion increases, the heat of detonation decreases. It means that the polymeric matrix has higher heat of combustion than the PETN.

Also, Semtex 1A, Sprängdeg m/46, and Formex P1 have higher heat of combustion than Semtex 10 and EPX-1. This result is mostly due to the presence of oily material in their polymeric matrix which increases their heat of combustion while Semtex 10 and EPX-1 contain polar plasticizers in their polymeric matrix which increase their heat of detonation.

\section{Conclusion}

From this study it was concluded that EPX-1 is a new plastic explosive that has compatible ingredients. EPX-1 has PETN crystals completely coated by the polymeric matrix. Sensitivities to impact and friction of EPX-1 are in the same level of most of the studied plastic explosives. EPX-1 has the highest detonation velocity of all the studied plastic explosives. The calculated detonation pressure and heat of detonation of EPX-1 are in the same level of Semtex 10 and higher than the rest of the studied plastic explosives. Some relationships had been studied and proved the good agreement between the calculated detonation parameters by EXPLO5 code and the measured parameters. EPX-1 is an interesting plastic explosive and is a candidate to be used in military applications.

\section{Conflict of Interests}

The author declares that there is no conflict of interests regarding the publication of this paper.

\section{References}

[1] A. Elbeih, J. Pachman, W. A. Trzciński, S. Zeman, Z. Akštein, and J. Šelešovský, "Study of plastic explosives based on attractive cyclic nitramines Part I. Detonation characteristics of explosives with PIB binder," Propellants, Explosives, Pyrotechnics, vol. 36, no. 5, pp. 433-438, 2011.

[2] A. Elbeih, J. Pachman, S. Zeman, P. Vávra, W. A. Trzciński, and Z. Akštein, "Detonation characteristics of plastic explosives based on attractive nitramines with polyisobutylene and poly(methyl methacrylate) binders," Journal of Energetic Materials, vol. 30, no. 4, pp. 358-371, 2012.

[3] A. Elbeih, J. Pachman, S. Zeman, and Z. Akštein, "Replacement of PETN by bicyclo-HMX in semtex 10," Problems of Mechatronics, vol. 2, no. 2, pp. 7-16, 2010.

[4] A. Elbeih, J. Pachman, S. Zeman, W. A. Trzciński, and Z. Akštein, "Advanced plastic explosive based on BCHMX compared with composition C4 and semtex 10," in Proceedings of the 14th Seminar of the New Trends in Research of Energetic Materials, p. 119, Brno, Czech Republic, 2011.

[5] A. Elbeih, S. Zeman, M. Jungová, and P. Vávra, "Attractive nitramines and related PBXs," Propellants, Explosives, Pyrotechnics, vol. 38, no. 3, pp. 379-385, 2013.

[6] A. Elbeih, S. Zeman, M. Jungova, and Z. Akstein, "Effect of different polymeric matrices on the sensitivity and performance of interesting cyclic nitramines," Central European Journal of Energetic Materials, vol. 9, no. 2, pp. 131-138, 2012.

[7] A. Elbeih, S. Zeman, M. Jungova, P. Vávra, and Z. Akstein, "Effect of different polymeric matrices on some properties of plastic bonded explosives," Propellants, Explosives, Pyrotechnics, vol. 37, no. 6, pp. 676-684, 2012.

[8] A. Elbeih, S. Zeman, and J. Pachman, "Effect of polar plasticizers on the characteristics of selected cyclic nitramines," Central European Journal of Energetic Materials, vol. 10, no. 3, pp. 339350, 2013. 
[9] Q.-L. Yan, S. Zeman, J. Šelešovský, R. Svoboda, and A. Elbeih, "Thermal behavior and decomposition kinetics of Formexbonded explosives containing different cyclic nitramines," Journal of Thermal Analysis and Calorimetry, vol. 111, no. 2, pp. 14191430, 2013.

[10] Q.-L. Yan, S. Zeman, A. Elbeih, and R. Svoboda, "Thermodynamic properties, decomposition kinetics and reaction models of BCHMX and its Formex bonded explosive," Thermochimica Acta, vol. 547, pp. 150-160, 2012.

[11] Q.-L. Yan, S. Zeman, and A. Elbeih, "Recent advances in thermal analysis and stability evaluation of insensitive plastic bonded explosives (PBXs)," Thermochimica Acta, vol. 537, pp. 1-12, 2012.

[12] Q.-L. Yan, S. Zeman, F.-Q. Zhao, and A. Elbeih, "Nonisothermal analysis of $\mathrm{C} 4$ bonded explosives containing different cyclic nitramines," Thermochimica Acta, vol. 556, pp. 6-12, 2013.

[13] Q.-L. Yan, S. Zeman, and A. Elbeih, "Thermal behavior and decomposition kinetics of Viton A bonded explosives containing attractive cyclic nitramines," Thermochimica Acta, vol. 562, pp. 56-64, 2013.

[14] Q.-L. Yan, S. Zeman, T.-L. Zhang, and A. Elbeih, "Nonisothermal decomposition behavior of Fluorel bonded explosives containing attractive cyclic nitramines," Thermochimica Acta, vol. 574, pp. 10-18, 2013.

[15] Q.-L. Yan, S. Zeman, A. Elbeih, and A. Zbyněk, “The influence of the semtex matrix on the thermal behavior and decomposition kinetics of cyclic nitramines," Central European Journal of Energetic Materials, vol. 10, no. 4, pp. 509-528, 2013.

[16] S. Zeman, A. Elbeih, and Q.-L. Yan, "Note on the use of the vacuum stability test in the study of initiation reactivity of attractive cyclic nitramines in Formex P1 matrix," Journal of Thermal Analysis and Calorimetry, vol. 111, no. 2, pp. 1503-1506, 2013.

[17] S. Zeman, A. Elbeih, and Q.-L. Yan, "Notes on the use of the vacuum stability test in the study of initiation reactivity of attractive cyclic nitramines in the C4 matrix," Journal of Thermal Analysis and Calorimetry, vol. 112, no. 3, pp. 1433-1437, 2013.

[18] Web site of Explosia Company, 2014, http://www.explosia.cz.

[19] M. Sućeska, "EXPLO5-computer program for calculation of detonation parameters," in Proceedings of the 32nd International Annual Conference of ICT, Karlsruhe, Germany, 2001.

[20] M. Krupka, "Devices and equipments for testing of energetic materials," in New Trends in Research of Energetic Materials, p. 222, University of Pardubice, 2001.

[21] V. Kucera and B. Vetlicky, "Investigation of the decomposition processes in single-base propellants under vacuum using minicomputer-controlled automated apparatus," Propellants, Explosives, Pyrotechnics, vol. 10, no. 3, pp. 65-68, 1985.

[22] T. R. Gibbs and A. Popolato, LASL Explosive Property Data, University of California Press, 1980.

[23] M. Suceska, Test Methods for Explosives, Springer, Heidelberg, Germany, 1995.

[24] D. J. Finney, Probit Analysis, Cambridge University Press, London, UK, 3rd edition, 1971.

[25] A. Elbeih, S. Zeman, M. Jungova, Z. Akstein, and P. Vavra, "Detonation characteristics and penetration performance of plastic explosives," in Theory and Practice of Energetic Materials, S. Li and P. Niu, Eds., vol. 9, pp. 508-513, Science Press, Beijing, China, 2011. 

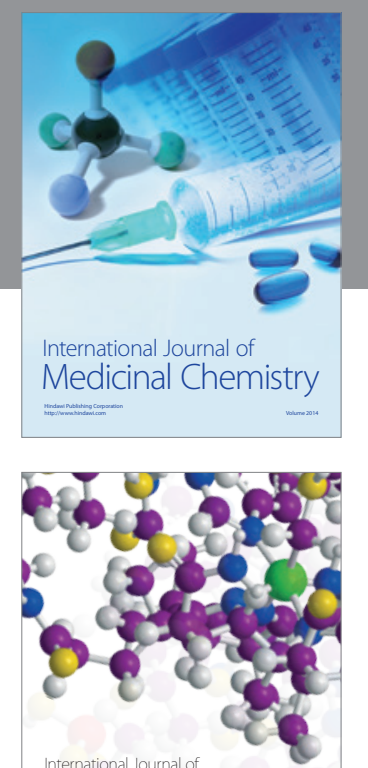

\section{Carbohydrate} Chemistry

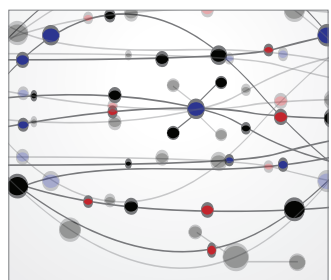

The Scientific World Journal
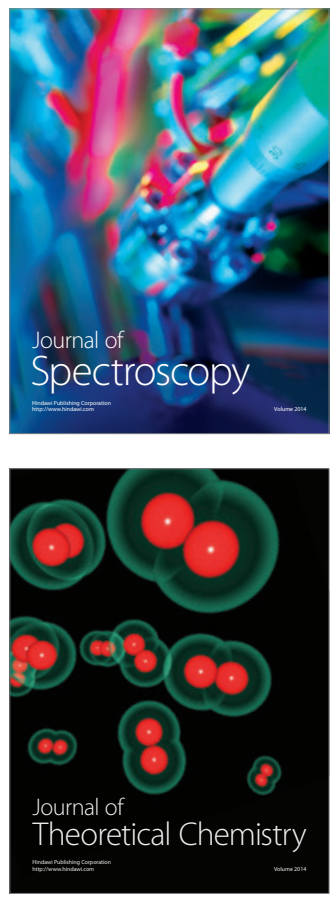
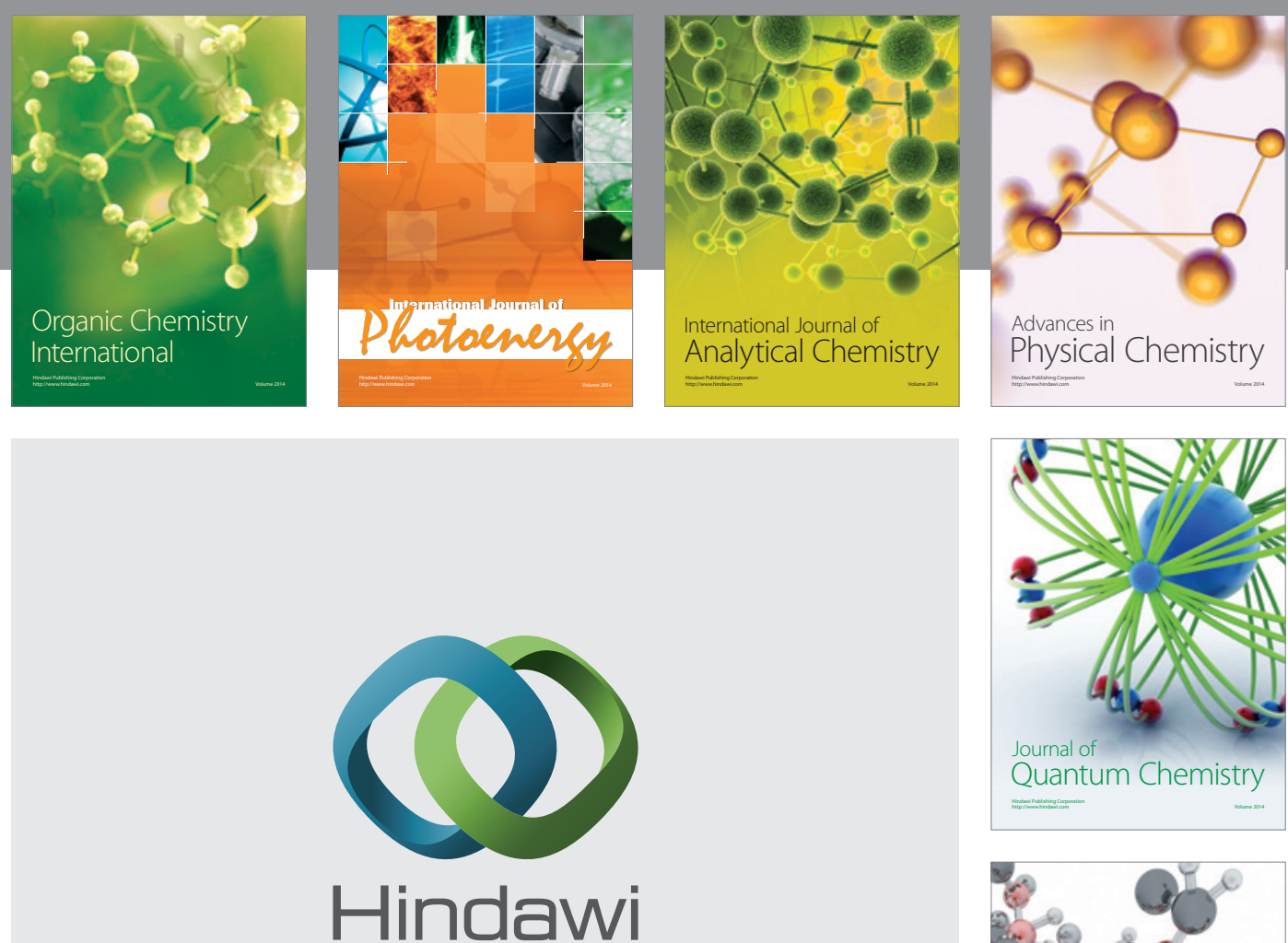

Submit your manuscripts at

http://www.hindawi.com

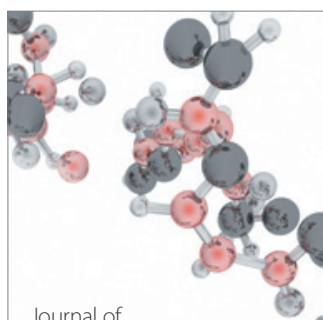

Analytical Methods

in Chemistry

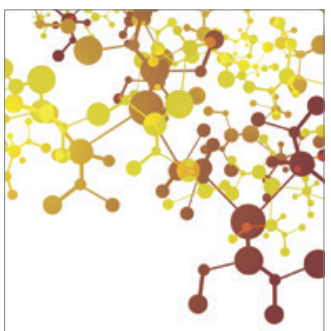

Journal of

Applied Chemistry

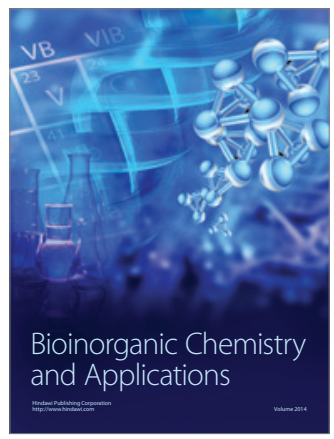

Inorganic Chemistry
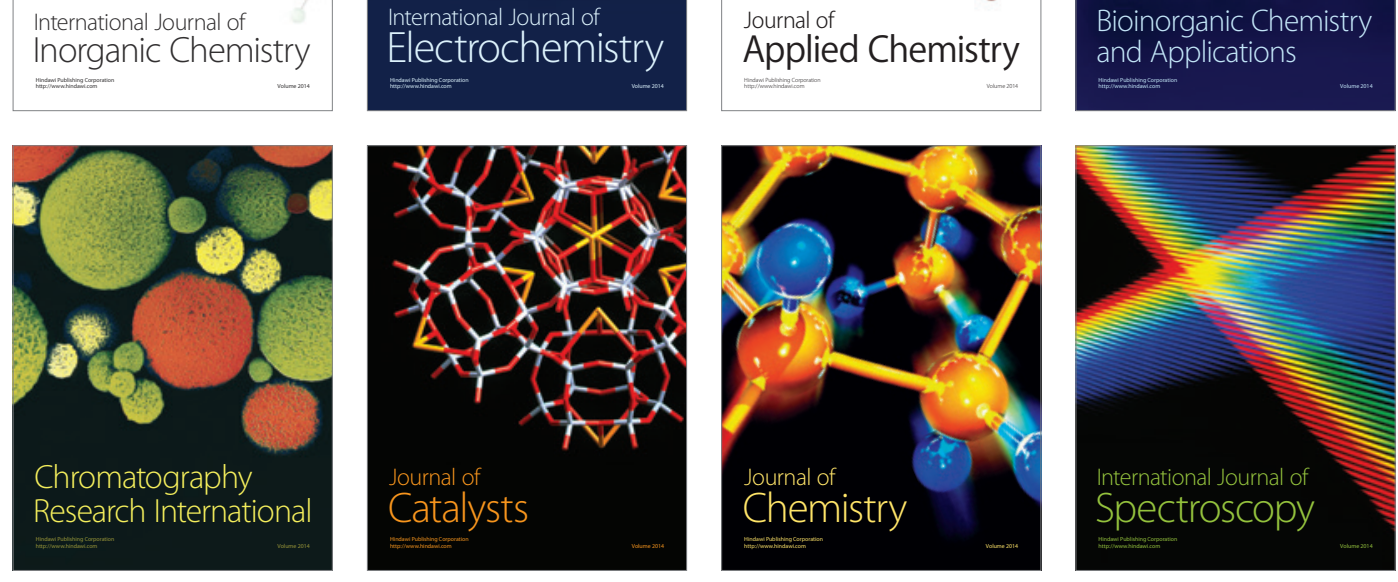